International Journal of Reliability, Quality and Safety Engineering Vol. 20, No. 5 (2013) 1303001 (2 pages)

(C) World Scientific Publishing Company

DOI: $10.1142 /$ S0218539313030010

\title{
Dr. Guangbin Yang
}

(1964-2013)

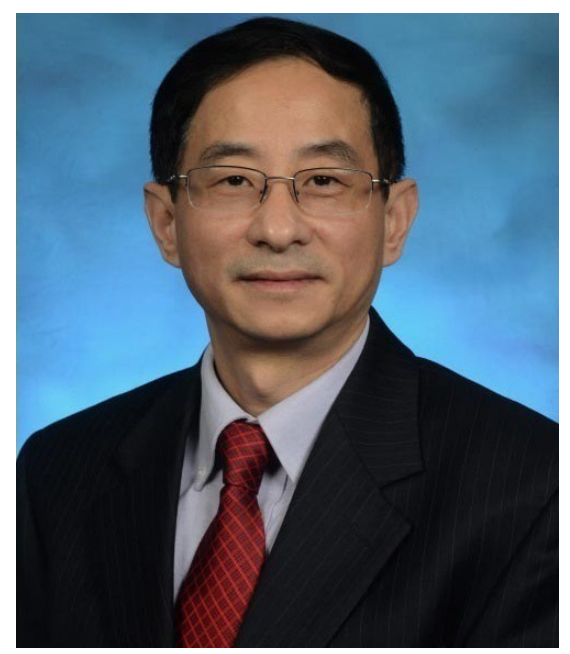

I was deeply saddened by the untimely loss of our dear friend and colleague Dr. Guangbin Yang who passed away on June 12, 2013.

Dr. Yang was born on August 22, 1964 in Jiexi, Guangdong, China. He graduated from Hangzhou Institute of Electronics Engineering in Hangzhou, China in 1986 with a Bachelor of Science in Mechanical Engineering. In 1989, he obtained Master of Science in Mechanical Engineering from Zhejiang University, Hangzhou, China. In August of 1995, he came to the United States to study and received his Ph.D. degree in Industrial Engineering from Wayne State University in 2000. After 2000, Dr. Yang entered into automotive industry to pursue his career development in the area of reliability engineering and product quality control. Dr. Yang proudly worked many dedicated years for Yazaki, Ford and Chrysler companies. He was a Technical Specialist in Ford PTO Reliability Engineering, and a supervisor in Ford PD Reliability and Quality Engineering, and a Walter P. Chrysler Technical Fellow in Chrysler.

Dr. Yang was an expert in the area of product life cycle reliability engineering and accelerated life testing in design. Among of his significant achievements and awards are: authored a textbook Life Cycle Reliability Engineering (Wiley, 2007), authored over 60 papers in reliability testing, the IEEE Reliability Society Engineer 
of the Year in 2002, ASQ Fellow Award in 2012, Ford Powertrain Achievement Award, "for Development of Efficient Design Verification Test Methods" (2010), and IEEE Senior Member since 1998. He had served as Associate Editor of the IEEE Transactions on Reliability; Editorial Board Member of the International Journal of Reliability, Quality, and Safety Engineering; Chair of Automotive Systems Committee, IEEE Reliability Society, 2003-2007; and Program Chair of ISSAT International Conference on Reliability and Quality in Design since 2008.

Dr. Yang was a great colleague, a sincere person, a man of many qualities. He lived a full and happy life with loves, good sense of humor and constant smiles. The Reliability community will miss him.

On behalf of the Editorial Board of this journal, our sincere condolences go to his loving family.

Hoang Pham

Editor-in-Chief 